\title{
Dalteparin and Rivaroxaban Sequential Use in Cancer Patients with Venous Thromboembolism
}

\author{
Lei Chen ${ }^{1}$, Qiang Chen², Minggao Zhu ${ }^{1}$ and Zhixiang Zhuang ${ }^{1}$ \\ ${ }^{1}$ Department of Oncology, The Second Affiliated Hospital of Soochow University, Suzhou, Jiangsu, P.R. China \\ ${ }^{2}$ Department of General Surgery, The Second Affiliated Hospital of Soochow University, Suzhou, Jiangsu, P.R. China
}

\begin{abstract}
Objective: To determine the effect and safety of sequential treatment with the low-molecular-weight heparin dalteparin and the direct oral anticoagulants rivaroxaban in patients with cancer- associated venous thromboembolism (VTE).

Study Design: Observational study.

Place and Duration of Study: Department of Oncology, the Second Affiliated Hospital of Soochow University, between January 2017 and September 2019.

Methodology: Patients with active cancer, diagnosed with VTE and who received sequential treatment with dalteparin and rivaroxaban, were retrospectively reviewed. Logistic regression analysis was used to identify risk factors associated with VTE recurrence.

Results: Ninety-nine patients with active cancer were enrolled in the study. The median delteparin treatment time was nine days (5-20 days), and 2.8 months (1-6 months) for rivaroxaban. Sixty (60.6\%) patients had eliminated VTE, and 39 $(39.4 \%)$ had persistent VTE, but with relieved symptoms. No major bleeding was observed. Eleven (11.1\%) patients had minor bleeding, including melena (5.1\%), hematuria (3.0\%), vaginal bleeding $(1.0 \%)$, gingival bleeding $(1.0 \%)$, and subcutaneous hemorrhage (1.0\%). During the 6 months follow-up period, one (1.0\%) developed pulmonary embolism, and seven (7.1\%) experienced recurrent VTE. Univariate logistic regression analysis showed that bleeding occurrence and anticoagulant treatment duration were the two significant factors affecting VTE recurrence $(p<0.05)$.

Conclusion: Maintenance of rivaroxaban after initial dalteparin treatment could effectively reduce the risk of VTE recurrence and was well tolerated by patients with cancer-associated VTE. However, in the clinical practice, the treatment duration is often insufficient, so it is essential to follow-up these patients to ensure sufficient treatment time.
\end{abstract}

Key Words: Venous thromboembolism, Low-molecular-weight heparins, Directly oral anticoagulants, Cancer.

How to cite this article: Chen L, Chen Q, Zhu M, Zhuang Z. Dalteparin and Rivaroxaban Sequential Use in Cancer Patients with Venous Thromboembolism. J Coll Physicians Surg Pak 2021; 31(03):294-297.

\section{INTRODUCTION}

Venous thromboembolism (VTE) is a common complication and the main cause of death in cancer patients. The incidence of VTE in cancer patients was reported to be $4 \%-20 \%,{ }^{1}$ which is four to seven times higher than in patients without cancer. ${ }^{2}$ There are several factors that may be responsible for the high incidence, such as the use of central venous catheters, and active anticancer treatments includin chemotherapy, antiangiogenic and anti-cancer interventional therapy. ${ }^{3-5}$

Correspondence to: Dr. Zhixiang Zhuang, Department of Oncology, The Second Affiliated Hospital of Soochow University, Suzhou, Jiangsu, P.R. China

E-mail: gt61019102@163.com

Received: November 14, 2020; Revised: February 06, 2021; Accepted: February 12, 2021

DOI: https://doi.org/10.29271/jcpsp.2021.03.294
Anticoagulation options recommended for the management of VTE in patients with cancer include low-molecular-weight heparins (LMWHs), the vitamin $\mathrm{K}$ antagonist (VKAs) warfarin, and direct oral anticoagulants (DOACs). ${ }^{6} \mathrm{LMWHs}$ have been the preferred monotherapy in the acute and maintenance phases of VTE; however, subcutaneous administration is not convenient and may cause poor compliance in long-term LMWH treatment. Therefore, combination treatments which include LMWH therapy, followed by warfarin or DOACs, are alternative options.6-8 Although warfarin is a traditional oral agent used in VTE, the international normalised ratio should be maintained at an interval of 2.0 to 3.0 during the treatment. ${ }^{9}$ DOACs including dabigatran, rivaroxaban and apixaban, are anti-hemophilic Xa inhibitors, which have similar reported safety and efficacy profiles for the treatment of VTE in cancer patients. ${ }^{10-12}$ These agents have been reported to be non-inferior to VKAs in patients with acute VTE. ${ }^{9,13}$

However, there is still no recommendation of LMWH treatments followed by rivaroxaban in the current guidelines. ${ }^{6}$ 
The primary objective of this study was to assess the safety of rivaroxaban during maintenance treatment. The secondary objectives were outcome of VTE after anticoagulation treatment and the incidence of recurrentVTE within six months.

\section{METHODOLOGY}

Potential study patients were identified by searching the color Doppler ultrasonography and electronic patient record system for the cancer patients diagnosed with acute VTE in the Second Affiliated Hospital of Soochow University, between January 2017 and September 2019. A total of 619 patients were identified. Active cancer was defined as a new diagnosis of cancer within six months before VTE occurrence, anticancer treatment within the previous six months, and metastatic cancer. The patients who had received LMWHs as initial treatment and who were switched to DOACs successfully were included. The treatment protocol used was 7-15 days standard subcutaneous administration of LMWHs, followed by rivaroxaban ( $20 \mathrm{mg}$ once daily) for 1 to 6 months. The anticancer treatments were not influenced by the VTE treatment and could be adjusted according to the oncologists' decisions.

Patients who died during treatment with LMWHs or had contraindications for rivaroxaban were excluded. Rivaroxaban contraindications included active gastrointestinal bleeding or creatinine clearance rate of less than $30 \mathrm{ml} / \mathrm{min}$. Patients who had received rivaroxaban treatment for less than one month were also excluded. Safety was determined by the incidence and severity of bleeding including major and clinically relevant non majorbleeding (CRNMB). ${ }^{14,15}$

Baseline characteristics, including age, BMI, gender, comorbidities, cancer type and stage, surgery 30 days before VTE, and systemic treatment were presented as percentages, and continuous variables were presented as mean with standard deviation (SD) and median (minimum-maximum). The safety of rivaroxaban and outcome of VET were expressed by frequency with corresponding $95 \%$ confidence intervals $(95 \% \mathrm{Cl})$. Age, gender, primary tumor type, tumor stage, comorbidities, systemic antitumor treatment, location of primary thrombus, surgery within 30 days, bleeding occurrence, outcome of primary thrombus and the persistence of anticoagulant therapy were tested using univariate logistic regression analysis. All analyses were performed using SPSS (version 25.0.0, IBM) with a significance level of $p<0.05$.

\section{RESULTS}

Altogether 99 patients met the inclusion criteria. Four patients had VTE combined with pulmonary embolism (PE), which was detected using a contrast-enhanced CT scan. The median age was 67 (34-84) years, there were 45 (45.5\%) male patients and $54(54.5 \%)$ female patients. The mean BMI was $21.6 \pm 1.4$ $\mathrm{Kg} / \mathrm{m}^{2}$. The most common comorbidities included hypertension $(27 / 99,27.3 \%)$ and diabetes mellitus $(6 / 99,6.1 \%)$. Four patients (4.5\%) had active infections when VTE occurred. The primary cancers included: 24 (24.2\%) gastric and esophageal cancers, 15 (15.2\%) gynecologic cancers,13(13.1\%) lung cancers, $9(9.1 \%)$ colorectal cancers, 9 (9.1\%) breast cancers,
8(8.1\%) cholangio-pancreatic cancers, 7 (7.1\%) prostate cancers, and $14(14.1 \%)$ other cancers. A total of 70 (70.1\%) patients had recurrent or metastatic disease. Within 30 days of VTE diagnosis, $20(20.2 \%)$ patients underwent tumor related surgery, and $6(6.1 \%)$ had deep vein catheterization. Seventy-one $(71.7 \%)$ patients received systemic treatments including chemotherapy alone $(60.6 \%)$ or anti-angiogenics with or without chemotherapy (11.1\%, TableI).

Table l: Patients' baseline characteristics.

\begin{tabular}{|c|c|}
\hline Age (median), (range) (year) & $67(34-84)$ \\
\hline $\mathrm{BMI}($ mean $\pm \mathrm{SD})$ & $21.6 \pm 1.4$ \\
\hline \multicolumn{2}{|l|}{ Gender } \\
\hline Male, N (\%) & $45(45.5 \%)$ \\
\hline Female, $\mathrm{N}(\%)$ & $54(54.5 \%)$ \\
\hline \multicolumn{2}{|l|}{ Comorbidities } \\
\hline Hypertension, N (\%) & $27(27.3 \%)$ \\
\hline Diabetes mellitus, N (\%) & $6(6.1 \%)$ \\
\hline Active infection, $\mathrm{N}(\%)$ & $4(4.0 \%)$ \\
\hline \multicolumn{2}{|l|}{ Location of primary thrombus } \\
\hline Upper extremity & $29(29.3 \%)$ \\
\hline Lower extremity & $66(66.7 \%)$ \\
\hline Combined with PE & $4(4.0 \%)$ \\
\hline \multicolumn{2}{|l|}{ Platelet distribution $\left(\times 10^{\wedge} 9 / \mathrm{L}\right)-\mathrm{N}(\%)$} \\
\hline$<125$ & $12(12.1 \%)$ \\
\hline $125-350$ & $82(82.8 \%)$ \\
\hline$>350$ & $5(5.1 \%)$ \\
\hline \multicolumn{2}{|l|}{ Cancer type } \\
\hline Gastric and esophagus, N (\%) & $24(24.2 \%)$ \\
\hline Gynecologic, N (\%) & $15(15.2 \%)$ \\
\hline Lung, N (\%) & $13(13.1 \%)$ \\
\hline Colorectal, N (\%) & $9(9.1 \%)$ \\
\hline Breast, N (\%) & $9(9.1 \%)$ \\
\hline Cholangiopancreatic, N (\%) & $8(8.1 \%)$ \\
\hline Prostate, N (\%) & $7(7.1 \%)$ \\
\hline Others, N (\%) & $14(14.1 \%)$ \\
\hline \multicolumn{2}{|l|}{ Disease stage } \\
\hline Early, N (\%) & $29(29.3 \%)$ \\
\hline Recurrence/metastasis, N (\%) & $70(70.7 \%)$ \\
\hline \multicolumn{2}{|c|}{ Surgery wthin 30 days before VTE diagnosis } \\
\hline Tumor related, $\mathrm{N}(\%)$ & $20(20.2 \%)$ \\
\hline Deep vein catheterization, $\mathrm{N}(\%)$ & $6(6.1 \%)$ \\
\hline \multicolumn{2}{|l|}{ Systemic treatment } \\
\hline Chemotherapy, N (\%) & $60(60.6 \%)$ \\
\hline Antiangiogenic therapy, N (\%) & $11(11.1 \%)$ \\
\hline
\end{tabular}

All the patients were followed up for 6 months or till the death occurred. The median duration of LMWH treatment was 9 (5-20) days, and 2.8 (1-6) months for rivaroxaban. VTE disappeared in $60(60.6 \%)$ patients after treatment; another 39 (39.4\%) patients had persistent VTE but they had symptomatic relief and vascular recanalization was not required. No major bleeding was observed. CRNMB occurred in 11 (11.1\%) patients, including $5(5.1 \%)$ melena, $3(3.0 \%)$ hematuria, 1 $(1.0 \%)$ vaginal bleeding, 1 (1.0\%) gingival bleeding and 1 (1.0\%) subcutaneous hemorrhage (Table II).

Seven (7.1\%) patients had recurrentVTE, and one (1.0\%) developed fatal PE during the 6-month follow-up. The logistic regression analysis results showed that the occurrence of bleeding and anticoagulant treatment duration were the two significant factors affecting VTE recurrence $(p=0.038$ and $p=0.012$ respectively, Table III). 
Table II: Safety analysis and outcome of VTE.

\begin{tabular}{|l|l|}
\hline Outcome & $60(60.6 \%)$ \\
\hline Disappeared, N (\%) & $39(39.4 \%)$ \\
\hline Persistent, N (\%) & $8(8.1 \%)$ \\
\hline Recurrence of VTE/PE, N (\%) & $7(7.1 \%)$ \\
\hline VTE, N (\%) & $1(1.0 \%)$ \\
\hline PE, N (\%) & 0 \\
\hline Safety & $11(11.1 \%)$ \\
\hline Major bleeding, N (\%) & $5(5.1 \%)$ \\
\hline Minor bleeding, N (\%) & $3(3.0 \%)$ \\
\hline Melena, N (\%) & $1(1.0 \%)$ \\
\hline Hematuria, N (\%) & $1(1.0 \%)$ \\
\hline Vaginal bleeding, N (\%) & $1(1.0 \%)$ \\
\hline Gingival bleeding, N (\%) & \\
\hline Subcutaneous hemorrhage, N (\%)
\end{tabular}

Table III: Univariate analysis of risk factors for VTE recurrence.

\begin{tabular}{|l|l|l|l|}
\hline Factor & Exp (B) & $\mathbf{9 5 \% ~ C l ~}$ & p-value \\
\hline Age & 0.93 & $0.86-1.01$ & 0.100 \\
\hline Sex & 0.30 & $0.04-2.49$ & 0.264 \\
\hline BMI & 2.28 & $0.86-6.05$ & 0.097 \\
\hline Primary tumor type & 1.08 & $0.71-1.64$ & 0.730 \\
\hline Tumor stage & 0.09 & $0.00-4.48$ & 0.229 \\
\hline Comorbidities & 1.26 & $0.48-3.27$ & 0.642 \\
\hline Systemic antitumor treatment & 6.78 & $0.63-73.23$ & 0.115 \\
\hline Location of primary thrombus & 0.91 & $0.12-6.74$ & 0.922 \\
\hline $\begin{array}{l}\text { Surgery within 30 days before } \\
\text { VET diagnosis }\end{array}$ & 1.41 & $0.16-12.87$ & 0.759 \\
\hline Bleeding occurrence & 38.12 & $1.22-1196.03$ & $0.038 *$ \\
\hline Outcome of primary thrombus & 0.59 & $0.04-8.01$ & 0.691 \\
\hline $\begin{array}{l}\text { Persistence of anticoagulant } \\
\text { therapy }\end{array}$ & 0.01 & $0.00-0.35$ & $0.012 *$ \\
\hline$* P<0.05$ & \multicolumn{3}{|l}{} \\
\hline
\end{tabular}

During the follow-up, 15 (15.2\%) patients died, among which no patient died of bleeding. One (1.0\%) patient died of PE, possibly because she took rivaroxaban for one month only. The other 14 (14.1\%) patients died of cancer-related complications.

\section{DISCUSSION}

In this study, the authors retrospectively evaluated the clinical outcomes of sequential treatment with LMWHs and rivaroxaban in patients with cancer-associated VTE in clinical practice. The results showed that no patient experienced major bleeding, $11.1 \%$ had clinically relevant minor bleeding, $8.1 \%$ had recurrent VTE, and inadequate anticoagulant treatment time and the occurrence of bleeding were the only two risk factors for VTE recurrence.

LMWHs have been recommended as the standard treatment in the acute and maintenance phases of VTE, ${ }^{6,7}$ but subcutaneous administration is often inconvenient in the maintenance phase. Compared to LMWHs, oral anticoagulants including VKA and DOACs are more convenient for outpatients. The CLOT trial showed that dalteparin reduced recurrent VTE by $50 \%$ compared to LMWHs followed by a VKA, hinting that continuous LMWH treatment was superior to VKA in VTE maintenance treatment. ${ }^{16}$ Oral rivaroxaban was reported to be noninferior to initial LMWH followed by VKA in the EINSTEIN trials. ${ }^{17,18}$ In the SELECT-D trial, rivaroxaban given as initial treatment for a total of six months accounted for relatively lower VTE recurrence ( $4 \%$ vs. $11 \%$ ) but higher CRNMB ( $6 \%$ vs $4 \%$ ), compared with dalteparin. ${ }^{19}$ In the
Hokusai-VTE Cancer open-label, non-inferiority clinical trial, cancer patients with VTE received either dalteparin for at least five days followed by oral edoxaban or subcutaneous dalteparin for at least six months. The results showed that the recurrent VTE rates were $7.9 \%$ vs. $11.3 \%$ in the edoxaban group and the dalteparin group respectively. The rate of major bleeding was higher with edoxaban than with dalteparin $(6.9 \%$ vs. $4.0 \%){ }^{20}$

The bleeding risk (11.1\%) in this study was slightly higher than that in the SELECT-D trial and the Hokusai-VTE Cancer trial, but the death risk did not increase. ${ }^{19,20}$ All patient symptoms were relieved well, and the sequential treatment was well tolerated. This treatment procedure was similar but not perfectly matched to the Hokusai-VTE Cancer trial procedure.

These results showed that the recurrent rate of VTE was 8.1\%, which was higher than the one reported by SELECT-D trial. However, therewere some limitations to thestudy due to its retrospective nature. The median LMWH treatment time was 9 days (5-20 days), and for rivaroxaban it was only 2.8 months (1-6 months), which was less than the recommended six months, suggesting that the outpatient compliance was often poor, and that treatment time was insufficient in the realistic clinical practice. ${ }^{21}$ The regression analysis proved that bleeding occurrence and inadequate anticoagulant duration attributed to VTE recurrence, which also suggested that bleeding occurrence may influence the patient's compliance leading to inadequate treatment time. With sufficient enough treatment time, the SELECT-D trial reported that tumor site and VTE type could predict VTE recurrence, which was not proven in this study.

\section{CONCLUSION}

Maintenance of rivaroxaban after initial LMWH treatment in patients with cancer associated VTE could reduce VTE recurrence effectively and is well tolerated. This treatment is very convenient for patients to be treated at home; and should be recommended to selected in patients with cancer associated VTE. However, it is also important to strengthen outpatient management and ensure sufficient treatment time in the realistic clinical practice.

\section{FUNDING:}

This work was supported by Suzhou Municipal Health Commission [SZYJTD 201804].

\section{ETHICALAPPROVAL:}

The study was approved by the Ethics Committee of the Second Affiliated Hospital of Soochow University.

\section{PATIENTS' CONSENT:}

Informed consent for patient information to be published in this article was not obtained, as a waiver was granted by the Institutional Review Board Committee since the retrospective nature of data collection.

\section{CONFLICT OF INTEREST:}

The authors have no conflicts of interest to declare.

\section{AUTHORS' CONTRIBUTION:}

LC, QC: Conception and design, drafting and final approval. 
LC and QC contributed equally.

MZ: Data acquisition and analysis and final approval.

ZZ: Conception and design, critical revision and final approval.

\section{REFERENCES}

1. Khorana AA, Francis CW, Culakova E, Kuderer NM, Lyman $\mathrm{GH}$. Thrombo embolism is a leading cause of death in cancer patients receiving outpatient chemotherapy. J Thromb Haemost 2007; 5(3):632-34. doi: 10.1111/j.15387836.2007.02374.x.

2. Heit JA, Spencer FA, White RH. The epidemiology of venous thromboembolism. J Thromb Thrombolysis 2016; 41(1): 3-14. doi: 10.1007/s11239-015-1311-6.

3. Verso M, Agnelli G. Venous thromboembolism associated with long-term use of central venous catheters in cancer patients. J Clin Oncol 2003; 21(19):3665-75. doi: 10.1200/ JCO.2003.08.008.

4. Khorana AA, Dalal M, Lin J, Connolly GC. Incidence and predictors of venous thromboembolism (VTE) among ambulatory high-risk cancer patients undergoing chemotherapy in the United States. Cancer 2013; 119(3): 648-55. doi: 10.1002/cncr.27772.

5. Ranpura V, Hapani S, Chuang J, Shenhong WU. Risk of cardiac ischemia and arterial thromboembolic events with the angiogenesis inhibitor bevacizumab in cancer patients: A meta-analysis of randomised controlled trials. Acta Oncol 2010; 49(3):287-97.doi: 10.3109/02841860903524396.

6. NCCN Guidelines: Cancer-Associated Venous Thromboembolic Disease (Version 1. 2019).

7. Hakoum MB, Kahale LA, Tsolakian IG, Matar CF, Yosuico VE, Terrenato I, et al. Anticoagulation for the initial treatment of venous thromboembolism in people with cancer. Cochrane Database Syst Rev 2018; 24(1):CD006649.doi: 10.1002/14651858.CD006649.pub7.

8. Farge D, Frere C, Connors JM, Ay C, Khorana AA, Munoz A, et al. 2019 international clinical practice guidelines for the treatment and prophylaxis of venous thromboembolism in patients with cancer. Lancet Oncol 2019; 20(10):e566-81. doi: 10.1016/S1470-2045(19)30336-5.

9. Schulman S, Kakkar AK, Goldhaber SZ, Schellong S, Eriksson $\mathrm{H}$, Mismetti $\mathrm{P}$, et al. Treatment of acute venous thromboembolism with dabigatran or warfarin and pooled analysis. Circulation 2014; 129(7):764-72. doi: 10.1016/ S1470-2045(19)30336-5. Ep

10. Kruger PC, Eikelboom JW, Douketis JD, Hankey GJ. Deep vein thrombosis: Update on diagnosis and management. The Medical journal of Australia 2019; 210(11):516-24.doi: 10.5694/mja2.50201.

11. Song AB, Rosovsky RP, Connors JM, Al-Samkari H. Direct oral anticoagulants for treatment and prevention of venous thromboembolism in cancer patients. Vasc Health Risk Manag 2019; 21;15:175-186.doi:10.2147/VHRM.S132556.

12. Wysokinski WE, Houghton DE, Casanegra Al, Vlazny DT, Bott-Kitslaar DM, Froehling DA, et al. Comparison of apixaban to rivaroxaban and enoxaparin in acute cancerassociated venous thromboembolism. Am J Hematol 2019; 94(11):1185-1192. doi: 10.1002/ajh.25604.

13. Agnelli G, Buller HR, Cohen A, Curto M, Gallus AS, Johnson $M$, et al. Oral apixaban for the treatment of acute venous thromboembolism. N Engl J Med 2013; 369 (9):799-808. doi: 10.1056/NEJMoa1302507.

14. Schulman S, Kearon C. Subcommittee on control of anticoagulation of the scientific, and standardisation committee of the international society on thrombosis, and haemostasis. Definition of major bleeding in clinical investigations of antihemostatic medicinal products in nonsurgical patients. J Thromb Haemost 2005; 3:692-94. doi: 10.1111/j.1538-7836.2005.01204.x.

15. Kaatz S, Ahmad D, Spyropoulos AC. Subcommittee on control of anticoagulation. definition of clinically relevant nonmajor bleeding in studies of anticoagulants in atrial fibrillation and venous thromboembolic disease in nonsurgical patients: communication from the ssc of the isth. J Thromb Haemost 2015; 13(11):2119-26. doi: 10.1111/ jth.13140.

16. Lee AY, Levine MN, Baker RI, Bowden C, Kakkar AK, Prins M, et al. Low molecular-weight heparin versus a coumarin for the prevention of recurrent venous thromboembolism in patients with cancer. N Engl J Med 2003; 349(2):146-53. doi: 10.1056/NEJMoa025313.

17. Bauersachs R, Berkowitz SD, Brenner B, Buller HR, Decousus H, Gallus AS, et al. Oral rivaroxaban for symptomatic venous thromboembolism. N Engl J Med 2010; 363(26): 2499-510. doi: 10.1056/NEJMoa1007903.

18. Büller HR, Prins $M H$, Lensin AW, Decousus $H$, Jacobson BF, Minar $\mathrm{E}$, et al. Oral rivaroxaban for the treatment of symptomatic pulmonary embolism. N Engl J Med 2012; 366(14):1287-97.doi: 10.1056/NEJMoa1113572.

19. Young AM, Marshall A, Thirlwall J, Chapman O, Lokare A, Hill $C$, et al. Comparison of an oral factor xa inhibitor with low molecular weight heparin in patients with cancer with venous thromboembolism: results of a randomised trial (SELECTD). J ClinOncol 2018; 36(20):2017-23. doi: 10.1200/JCO.2018.78.8034.

20. Raskob GE, Es NV, Verhamme P, Carrier M, Nisio MD, Garcia D, et al. Edoxaban for the treatment of cancerassociated venous thromboembolism. N Engl J Med 2018; 378(7):615-24.doi: 10.1056/NEJMoa1711948.

21. Ay C, Beyer-Westendorf J, Pabinger I. Treatment of cancerassociated venous thromboembolism in the age of direct oral anticoagulants. Ann Oncol 2019; 30(6):897-07. doi: 10.1093/annonc/mdz111. 